\title{
Repensar a innovación no rural a través das Experiencias Productivas Innovadoras
}

\author{
Rethinking innovation in rural areas through \\ Innovative Productive Experiences \\ LOURENZO FERNÁNDEZ PRIETO \\ Universidade de Santiago de Compostela \\ https://orcid.org/0000-0003-3206-2428 \\ louremzo.fernadez@usc.es \\ XAVIER SIMÓN \\ Universidade de Vigo \\ https://orcid.org/0000-0002-5667-0367 \\ xsimon@uvigo.gal \\ FRAN QUIROGA \\ Universidade de Santiago de Compostela \\ https://orcid.org/0000-0002-8409-6710 \\ fran.g.quiroga@gmail.com
}

\section{RESUMO}

A través deste artigo determinamos, identificamos e caracterizamos as Experiencias Produtivas Innovadoras (EPIs) como manifestacións dos procesos de ecoagroinnovación que se están dando no rural galego na actualidade. Este texto supón un compromiso da Rede ReVOLTA de xerar mecanismos de devolución do coñecemento, cos que devolver a información coa que traballamos da man das experiencias produtivas coas que fomos compartindo espazos de intercambio e diálogo e atende á vez a necesidade de conceptualizar as EPIS co obxectivo de que poidan replicarse e amplificarse estes procesos/experiencias.

Palabras clave: Rural, innovación, sustentabilidade, agroecoloxía.

\section{Abstract}

Through this article, we determine, identify and characterize Innovative Productive Experiences (EPIs) as demonstrations of the ecoagrainnovation processes what are being carried out in rural Galicia nowadays. This research represents a commitment by the ReVOLTA Network to generate 
mechanisms for the return of knowledge. We have been working with productive experiences with which to return the information we work with on the productive experiences creating shared spaces for exchange and dialogue. The aim is also try to conceptualize EPIS to increase and replicated these process and experiences.

Keywords: rural, innovation, sustentability, agroecology.

Este artigo trata da innovación no rural e da súa identificación, queremos dar conta da indagación sobre un rural innovador coñecido pero á vez descoñecido pero, sobre todo, pouco valorado. Nunha sociedade urbana como a galega que olla ao rural para ver "feismo" e confirmar un suposto atraso atávico ou outras queixas e lamentos consuetudinarios, nós enfocamos o presente rural coa ollada da innovación de longo prazo para descubrir emprendementos ecoagroinnovadores que identificamos e desvendamos dende a Rede Revolta de Agroecoloxía e Historia, unha rede pluridisciplinar conformado por varios grupos de investigación ${ }^{1}$. Nesta presentación, que recolle unha parte da experiencia de Revolta, mesturamos transdisciplinarmente na autoría a aproximación do historiador do cambio tecnolóxico contemporáneo, a do economista ecolóxico e máis a do investigador militante.

Concebimos este artigo como unha interface coa que dar conta da ecoagroinnovación que se está dando en Galiza da man de diversas experiencias, determinadas previamente por un marco epistemolóxico no que se insire este xiro produtivo. Grazas ás Experiencias Produtivas Innovadoras (EPIs) podemos identificar e determinar cales son as características que as definen. Este artigo é un compromiso da Rede de xerar mecanismos de devolución do coñecemento, cos que devolver a información coa que traballamos da man das expereriencias produtivas coas que fomos compartindo espazos de intercambio e diálogo.

Logramos identificar o emprendemento social e toda unha exhibición de capacidades que cómpre presentar e explicar, porque son as compoñentes necesarias para construír un futuro sustentable: capacidades de manexo produtivo do territorio, de coñecemento transxeracional do medio e a capacidade de desenvolver proxectos ambiciosos e sustentables. E non menos importante, iniciativas coa capacidade de activar ás comunidades nas que están inseridas.

1 No período 2018-2019 a rede está conformada polos grupos ECOAGRASOC,Grupo de Investigación en Economía Agroalimentaria e Medioambiental, Desenvolvemento Rural e Economía Social (USC); HISTAGRA, Grupo de Historia Agraria e Política do Mundo Rural. Séculos XIX e XX (USC); GIEEAH, Grupo de Investigación en Economía Ecolóxica, Agroecoloxía e Historia (UVIGO); COSMERUN, Grupo de investigación en construcción sustentable para o medio rural e natural (USC); GESPIC, Grupo de Estudios de Historia Empresarial e Sectorial. Pesca, Industria e Comercio (USC); LABORATE, Laboratorio do Territorio (USC); GALABRA, Grupo de Investigación Galabra en Estudos Culturais (USC) e AGRONOMÍA, Grupo de investigación en agronomía.(USC) 
Chamamos Experiencias Produtivas Innovadoras (EPIs) a esas iniciativas rurais que buscamos, identificamos e avaliamos dende a Revolta ${ }^{2}$, aproveitando a plural capacidade de diagnóstico experto dos seus grupos, en termos históricos, ambientais, económicos, territoriais ou sociais. Describiremos o proceso de indagación, de selección e de modelización dunha EPI, definindo os trazos que posúen para consideralas como tal. Finalmente presentamos algúns resultados e conclusións.

\section{MARCO EPISTEMOLÓXICO}

O medio rural, non é un espazo inmutable, está transformandose vertixinosamente. Presenta unha dinámica entrópica, tendente á desorde. A consideración do que é a evolución, o progreso ou a innovación ten mudado ao longo do tempo; cómpre resituar polo tanto que se entende por innovación no rural e como estas mudanzas están afectando na actualidade ao medio rural e a quen reside alí. A capacidade de adaptación ás mudanzas é polo tanto unha cuestión que ten que ser abordada polos estudos cuxos obxectos epistémicos sexan o medio rural. A agroecoloxía e unha visión ecolóxica da economía, o cambio tecnolóxico e os novos valores éticos obrigan a un novo enfoque. A agroecoloxía enténdese como a aplicación dos principios ecolóxicos no deseño e xestión de agroecosistemas nun contexto social e político diferente ao actual. A Agroecoloxía require a transformación tecnolóxica das formas de producir pero tamén a mudanza sistémica das formas de distribuír e dos procesos de toma de decisións no ámbito do sistema agroalimentario (Méndez E. V., Bacon C. M., Cohen R., 2013). Defende unha nova ética alimentaria, unha nova forma de relacionar os sistemas alimentarios co resto dos sistemas, incluído o ambiental, onde os axentes, rurais e urbanos, convértense en actores centrais das dinámicas do seu propio desenvolvemento (Altieri, M. 1983).

En moitas ocasións tense considerado a innovación como aquelo que produce unha mellora, e nesta visión a tecnificación e a mecanización ían moldeando a terra, considerando que a "eficiencia" so ía vir pola mellora na maquinaría. Eís a visión paradigmática do vello modelo da revolución verde implantado despois de 1945 e triunfante como guía da modernización na segunda metade do século XX. O desenvolvemento planetario deste modelo deu lugar a procesos que foron suplantando os saberes locais, as diversidades de formas de producir adaptadas ás condicións físico climáticas, as formas comunais de xestión, as variedades de sementes e as razas animais, a diversidade das escalas nas que se operaba, a multiplicidade de sistemas que se manexaban e a diversidade de obxectivos que se perseguían.

Todo ese know how que neste recuncho de Europa podemos denominar labrego, que fora adquirido ao longo do tempo e transmitido con sucesivas innovacións de xeracións

2 http://revolta.usc.gal/ 
en xeracións en base a métodos non pautados en moitos casos, pero nos que o ensaio, a proba e o erro e a incorporación de novos coñecementos, produtos e formas de xestión estaban presentes e favorecían a adaptación tecnolóxica ao medio foron relegados, considerados "o atraso". Deste xeito, na segunda metade do século XX deuse unha ruptura na transmisión transformadora do coñecemento, que ademais era (e debe ser) a custe cero (Daly, H.E. 2012). Así a subalternización dos saberes labregos foi provocando que esas formas de relación coa natureza, cos ciclos da vida ou a xestión da terra como natureza transformada para producir en equilibrio coa presión demográfica foran considerados como o ineficiente ou o atrasado, como o tradicional e propio dun pasado que non daba pasado e polo tanto destruílos converteuse en condición para garantir a modernización: a conversión en moderno do que era tradicional e atávico e non quería ser moderno. A forza da idea de atraso referida ao medio rural é tal que aínda en moitas ocasións pódese ler como se asocia rural a atraso, e por iso é preciso, dende estes paradigmas, xa que os labregos e labregas non saben facer o seu traballo, un desenvolvemento rural pulado dende fora, da man de técnicos que non teñen nada que aprender senón só moito que ensinar. Porque teñen a verdade absoluta.

A perda -destrución en realidade- de coñecementos locais, e das formas de vida asociadas, non viu de forma illada senón que responde a aquilo que Vandana Shiva (2008, 19) ten afirmado de "ademais de volver invisible ao coñecemento local, declarándoo inexistente ou ilexítimo, o sistema dominante tamén fai desaparecer as alternativas, borrándoas ou destruíndo a realidade que procuraban representar". A pensadora india ten usado a metáfora do monocultivo da mente coa que ilustra como o sistema "científico" despraza a esas outra formas de relacionarnos co espazo que habitamos, así como todos eses saberes transmitidos de xeración en xeración. Este fenómeno insírese dentro daquilo que foi chamado Revolución Verde, definida como o "período marcado pola xeración de coñecementos tecnolóxicos destinados à agropecuaria do mundo enteiro e sistematizados en paquetes tecnolóxicos abranxindo a área da química, da mecánica e da bioloxía" (Vilas, F. Prieto e Simón, 1998,7) e que non ten acadado aqueles obxectivos que dalgunha maneira buscaban lexitimalo, que non eran máis que acabar coa fame. E pola contra si teñen provocado unha éxodo masivo e forzado do rural que en moitos países identifícase como descampesanización, proceso que ten sido moi acusado no caso galego, onde tal e como sinala Fernández Prieto $(2015,256)$, con datos de Edelmiro López Iglesias, nos últimos 50 anos tense reducido nun $80 \%$ o número de explotacións agrarias (421mil en 1962, 81 mil en 2009), nun proceso de cambio que definimos como abandono forzado e que inclúe un desprezo do pasado e do traballo agrario. E non foi menor tampouco o impacto ambiental causado pola revolución verde, na forma de contaminación atomosférica, do medio acuático e de contribución ao cambio climático.

Así, con este proceso de industrialización alimentaria, caracterizado por ser un modelo fordista de produción e distribución alimentaria, provócanse un conxunto de problemas ambientais e sociais que cómpre afrontar (Ripple W. J. et al., 2017). Fronte a eses procesos industrializados de produción e distribución alimentaria a nivel global agroman 
novos procesos sociais que se encadran dentro de dinámicas de transición agroecolóxica. As fortes tensións que se están dando en diferentes lugares do planeta como as folgas polo dereito a auga, as crises alimentarias nos países pobres ou os problemas alimentarios nos países ricos derivados da presenza masiva da "comida lixo", os movementos sociais, en diferentes partes do Sur Global, como Brasil, en defensa da terra, ou as diversas reaccións sociais ao propio cambio climático, están manifestando, nunca mellor dito, a necesidade de impulsar outros sistemas alimentarios que garantan a sustentabilidade social, económica e ambiental do sistema alimentario e, por extensión, do propio Planeta Terra (Rockström, J. et al., 2009).

Xa en 1978 Schumacher alertaba en Lo pequeño es hermoso $(1978,98)$ “a tendencia das cousas e o consello dos expertos está na dirección exactamente oposta, orientase hacia a industrialización e a despersonalización da agricultura, hacia a concentración, a especialización e todo tipo de dilapidación material que permita aforrar traballo. Substitúese o coñecemento da natureza por unha concepción da mesma como simple depositaria de variables físicas (solo, clima) nas cales aplicar as correspondentes tecnoloxías agrícolas Como resultado, o hábitat humano, lonxe de humanizarse e ennobrecerse polas actividades agrícolas do home, convértese nun lugar de aburrimento ou se degrada ata a fealdade". Fronte a esta tendencia fóronse dando procesos para reverter esta situación, que poderían integrarse nunha transición agroecolóxica. Nos últimos anos están emerxendo unha morea de proxectos empresariais no ámbito rural que destacan por unha valorización que vai máis alén do meramente económico e que reivindica outras formas de producir sustentables, con valores sociais e ambientais ${ }^{3}$. Cómpre coñecer este cambio social agroecolóxico dende una perspectiva integral, na que estean presentes olladas dende a enxeñería, a historia, a bioloxía, as ciencias sociais, así como do estudo das políticas públicas, o que permite acercarnos dunha forma holística a este proceso dende un punto de vista multidiscilplinar. Esta debe ser unha perspectiva agroecolóxica, no sentido apuntado por Susanna B. Hecht quen considera que "a agroecoloxía a miudo incorpora ideas sobre un enfoque da agricultura máis ligado ao medio ambiente e máis sensible socialmente; centrada non so na produción se non tamén na sostenibilidade ecolóxica do sistema de produción" (Altieri, 1999, 17). Nesta perspectiva agroecolóxica o control local dos recursos, a converxencia entre os actores sociais e as distintas formas de conectividade entre eles convértense nos elementos fundamentais das propostas de desenvolvemento.

A pesar se que según M. Cuéllar e E. Sevilla a agroecoloxía "tiene una dimensión integral a partir de la cual aborda los procesos productivos y distributivos del ámbito agroalimentario" $(2013,46)$, consideración que compartimos, neste artigo so nos centramos nos procesos produtivos e especialmente aqueles que se sitúan dentro do paradigma da ecoagroinnovación, entendido este como ese proceso de mellora continua e adaptación

3 Na Galiza existen diversos exemplos des tipo de iniciativas. Por exemplo Monte Cabalar, n'A Estrada (http://montecabalar.com/) ou as iniciativas desenvolvidas pola Comunidade de Montes Veciñais en Man Común de Zobra, Lalín (Simón, X. e Copena D, 2012) 
ás necesidades concretas que se está dando na transición agroecolóxica na que nos situamos, e que poderiamos cualificar como un proceso de transformación reflexiva (Sonnino, R. Et al, 2016). Un proceso de transformación adaptativa que deu lugar a procesos de intensificación produtiva con intervención da ciencia no marco da agricultura orgánica e que foi descrito xa para o mundo labrego anterior a 1940 (Fernández Prieto L., 1992) e analizado nos seus procesos de longo prazo (Soto D., 2006) e valorado nas súas capacidades e nos seus límites produtivos en termos de fertilización e manexo do territorio (Corbacho B. (2017).

\section{AS EXPERIENCIAS PRODUTIVAS INNOVADORAS COMO MANIFESTACIÓN EMPÍRICA DA AGROECOLOXÍA}

Dentro deste fenómeno actual de ecoagroinnovación, as experiencias produtivas innovadoras (EPIs) veñen representar estas manifestacións emerxentes deste proceso, podendo contemplarse como una unidade de relación económica-ambiental máis ecolóxica, saudable, e con maior valor engadido, cunha dimensión socio-temporal fundamental para o seu desenvolvemento. Esta unidade caracterizaríase por una proposta de beneficio económico dentro dun marco socio-temporal e ecosistémico onde predomina una actividade básica (cotiá) de produción de bens, fuxindo de dogmatismos produtivistas e tecnolóxicos, e con baixos fluxos metabólicos.

Outra variable a considerar é a relación que se establece nas EPIs directamente entre o espazo e actividade nas que existe unha maior concienciación na interacción responsable co espazo, conciencia de pertenza e interacción cun espazo definido, e temporal e socialmente determinado.

No proceso de indagación da rede Revolta foi preciso intentar determinar eses mínimos comúns que comparten estas experiencias produtivas innovadoras (EPI) e que nos permitan caracterizar este proceso para, a través desta visión xeral, identificar e explicar eses casos particulares que están agromando.

Mais precisamos dalgunha discusión sobre o concepto de innovación que relacione o concepto de resistencia como instrumento innovador, no que se verifica, como a través da resiliencia, danse prácticas innovadoras que adoptan un carácter endóxeno pola vía da adaptación local por parte dos propios labregos, ou porque saen dos propios labregos, quen son quen de facilitar eses proceso de innovación a través dunha aparente resistencia, que non é máis que unha capacidade de innovar. A este respecto, Rogers (2003) define unha idea ou práctica innovadora como aquela que é «percibida como nova por un individuo». De acordo con esta definición, non é realmente relevante que esta non sexa «obxectivamente» nova, senón o feito que que así o perciban determinadas persoas, nin é necesario que estea asociada a desenvolvemento tecnolóxico ou xeración de coñecemento.

Neste sentido é importante sinalar tamén a necesidade de probar a pequena escala a innovación proposta co obxectivo de superar o custe do ridículo, coa intención de escalar 
posteriormente o proceso e tamén a necesidade de innovar en comunidade, que é quen lle vai dar ese valor a ese proceso, quen lexitimrá dalgunha maneira que se da un proceso ecograoinnovador.

Sobre a relación entre resistencia e innovación, resistencia fronte a unhas innovacións e adaptación e innovación endóxenas respecto doutras e sobre o poder explicativo desas resistencias para entender os procesos de nnovación endóxenos hai unha liña de traballo historiográfico esclarecedora para o período do século anterior á revolución verde en diferentes realidades rurais Fitzgerald (2003).

\section{A CARACTERIZACIÓN DAS EPIS, TRAZOS DEFINITORIOS}

A Rede ReVOLTA ten como obxectivo artellar lugares de encontro entre o persoal investigador dos grupos que forman parte da rede. Entre as accións que leva a cabo está o de procurar definir o universo das Experiencias Productivas Innovadoras, para iso desenvolveu unha metodoloxía que segue a seguinte secuencia:

a) Partindo dos principios definitorios da agroecoloxía, os membros da Rede e expertos alleos realizaron unha proposta de actividades produtivas de carácter innovador que se desenvolven no territorio galego.

b) A coordinación da rede xunta toda a información secundaria existente sobre esas experiencias e consulta con axentes clave (líderes locais, responsábeis sectoriais, sindicatos agrarios, investigadores...) para dotar de contido a cada proposta. No caso de ser necesario (foino case nun $70 \%$ dos casos) provócase un encontro directo cos responsábeis das experiencias propostas para profundizar no nivel de coñecemento sobre as mesmas.

c) Realízase encontros nos que os participantes (membros da rede, expertos, axentes innovadores, etc) dialogan sobre a natureza de cada unha das actividades propostas seguindo as pautas marcadas no cuestionario elaborado pola coordinación da rede. Ao longo do 2015 e 2016 na rede ReVOLTA fóronse sucedendo unha serie de encontros coas Experiencias Productivas Innovadoras (EPI). Estas sesións de traballo tiñan como obxectivo coñecer con moita maior profundidade cales son os retos, recursos, dificultades e ameazas ás que se enfrontan estas experiencias.

d) Os resultados obtidos deste proceso son sometidos a avaliación externa por expertos que non participaran nas fases previas. Todo elo provocou a acumulación de coñecemento que nos permitiu trazar un mapa da realidade do rural innovadora de hoxe en día. As experiencias coas que participamos nos encontros foron: MVMC O Carballo / Arqueixal / CAP A Coruña / Ribeiregas / Labregos de Lugo / Vida de Aldea / Cortes de Muar / Gonzalo Sánchez / Coop A Capela / Souto Activo / Lagar da Ribela / Abonos Lourido / O Pomariño / Xan Pouliquen 
/ Leite O Alle / Pan de Mar / SAT A Pementeira / Gandería Quintian / DOP San Simón / Galletas da Veiga / Adega Diego de Lemos / PROMAGAL.

e) Con toda a información recollida a coordinación da rede realiza unha primeira proposta de Experiencias Produtivas Innovadoras. Das 22 experiencias seleccionáronse as dez EPIS que mellor atendían aos criterios diferencias que explicamos de contado. Para iso os investigadores cubriron unha ficha na que sinalaban nunha escala de opinión do 0 ao 10 como se comportaban estas experiencias ao redor dos items a través do cuestionario colaborativo https://ethercalc.org/3w717iopsipj.

f) Para seleccionar estas 10 Experiencias Productivas Innovadoras como mostra principal da actividade innovadora do medio rural galego seguíronse dous criterios:

1. Ordenación polo valor medio obtido para o conxunto dos indicadores.

2. Variabilidade na concordancia dos avaliadores (CATRO) empregando os valores do coeficiente de variación (CV\%).

O primeiro criterio estableceuse a partir da ordenación de maior a menor da valoración conxunta de avaliadores e de variables. O segundo empregouse partindo da hipótese que é "mellor" a escolla daquelas EPIs, que sendo a máis valoradas, teñan tamén unha maior concordancia (menor CV) nas valoracións dos "expertos". Neste caso o ideal é que houbera unha correlación continua negativa entre os valos medios e os coeficientes de variación, que é o que se dá no noso caso, xa que temos unha (r2 (Pearson) = - 0,964, $\mathrm{p}<0,001)$, mais non é exactamente continua, é dicir, as dez primeiras EPIs máis valoradas non son tamén as dez primeiras cos menores $\mathrm{CV}$.

Así as 10 EPIS seleccionadas foron:

MVMC O Carballo / Arqueixal / CAP A Coruña / Ribeiregas / Labregos de Lugo / Vida de Aldea / Coop A Capela / Souto Activo / Abonos Lourido / O Pomariño.

A través da análise empírica destas experiencias podemos considerar cales son os trazos comúns das EPIs do medio rural galego, é dicir, aquelas características que determinan a existencia dunha experiencia produtiva innovadora, e estas son:

\section{Reivindicación de valores socio-ambientais ademais do económico}

Fronte a visión de empresa de maximización de beneficios como único e universal criterio, nas EPIs reivindícanse outros obxectivos. O principal é que estas actividades deben ser realizadas en harmonía coa natureza: son un subsistema socioeconómico dun sistema maior, o sistema ambiental. As EPIs alén do propio obxectivo económico, o cal tamén é posible diferenciar alo mesmo entre crecemento económico e supervivencia, comparten valores ambientais, de o aproveitamento de saberes aínda coñecidos e ás veces resilientes ou ás veces mesmo a recuperación de saberes xa esquecidos propios do marco 
da agricultura orgánica e de outras formas de vida máis sustentables e apegadas á terra. Procuran "facer un ben á comunidade". A valorización polo tanto non ven so por unha cuestión económica, hai outros obxectivos que dan valor aos procesos que se desenvolven nas comunidades rurais. Daquela os incentivos son ideolóxicos, de identidade e económicos, como forma de obter unha renda básica e digna.

\section{Aposta polo común e polo local}

Trabállase coa comunidade local, sen rexeitar alianzas con comunidades "externas". Xérase unha comunidade de actores que lexitiman as accións que se desenvolven dende este tipo de experiencias, procuran gañarse a confianza co entorno. Conéctanse consumidores con produtores, pero tamén produtores entre si, e consumidores que comparten decisións. En moitos casos, fronte ás certificacións emitidas por organismos burocráticos alleos, na transición agroecolóxica que representan as EPIs prímanse outras lexitimidades garantidas mediante as vontades outorgadas polas comunidades implicadas nos procesos. Esta aposta situase na liña da trazabilidade por confianza.

\section{Recuperación de memoria sobre manexos cooperativos/comunais.}

Nas novas formas de producir e consumir asociadas aos procesos de transición agroecolóxica recupéranse aqueles procesos comunais de manexo e xestión comunais propios do rural galego, que foran substituídos ao premiar procesos máis mecanicistas. Non ten porqué retrocederse no tempo senón que se trata de rescatar dinámicas organizativas, recuperando procesos de traballo comunitario, mecanismos de entreaxuda, mesmo á veces asimétricos, pero sempre dominados por lóxicas horizontais e aplicando o apoio mutuo entre a veciñanza como mecanismo para conector entre individuos. Prácticas que á vez teñen a consecuencia de xerar ou fortalecer identidades locais e comunitarias, de aldea ou de parroquia que afortalan o capital social local. As EPIs combinan en diferentes graos estas praxes comunais coa incorporación de novas tecnoloxías.

\section{Pluriactividade" fronte a hiperespecialización}

Fronte a visión hexemónica da hiperespecialización característica do actual sistema económico, nestas experiencias produtivas innovadoras destaca a lóxica da pluriactividade, os promotores son tanto produtores, como xestores, como vendedores e a propia actividade da explotación é variada. Ademais na maioría dos casos compaxinan as accións propias da experiencia con outras como poden ser a formación, o turismo sostible, etc. A complementariedade de rendas é un feito definitorio destas EPIs.

\section{Uso tecnoloxías endóxenas/tecnoloxías propias}

Adáptanse as ferramentas agrícolas, fedellase nelas, múdanse os usos, adáptanse ás necesidades, a actualmente denominada cultura maker no rural reivindica a capacidade de hackear as aparellos para conseguir que estes atendan ás necesidades máis concretas. 


\section{Innovación tecnolóxica, social e comercial}

Innovación na propia forma de organizar a comercialización, destacando na maioría dos casos por unha innovación ben a través de grupos de consumo, como por unha aposta na comercialización directa. Á vez a xestión e organización do traballo superan a visión fordista e de cadea e apostase por modelos máis democráticos na toma de decisións, así como procesos máis horizontais e non tan xerarquizados como nos modelos tradicionais de empresa.

\section{Combinación de coñecemento adaptativo}

Combinación de coñecementos adaptativos, mais cércanos ás metodoloxías de aprender facendo, pero que combinan cun nivel alto de formación previo, o que facilita unha maior capacidade de aprendizaxe para adaptarse ás necesidades locais nas que insiren os proxectos innovadores. Coñecementos adaptativos e metodoloxías de aprender facendo que son propias das prácticas labregas e campesiñas.

\section{Redes de cooperación}

Impulso de redes con outros espazos e movementos activos da sociedade que apostan polo común, polo pequeno. Vincúlanse coas súas comunidades que ideoloxicamente sexan máis afíns. Participan en mercados sociais e acércanse a procesos de innovación social e de aposta polo ben común.

\section{Capacidade de resiliencia}

Capacidade de resiliencia, tanto para vencer as resistencias das comunidades nas que se insiren, onde é preciso gañarse a confianza, como dos mercados, onde procuran coconstruír novos canais de comercialización, alleos aos das grandes cadeas que dominan o mercado alimentario.

Reivindicar o propio, o micro, o lugar, o de abaixo, o pequeno como contrapeso a procesos máis globalizados que impregnan a produción e distribución máis hexemónica do sistema alimentario mundial actual.

\section{Reactivación de recursos abandonados}

Aqueles recursos que ficaron esquecidos na industrialización da alimentación s on recuperados na procura dunha valorización que poida ser tida en conta polos consumidores.

\section{Carácter reprodutible}

Unha das cuestión que se tivo en conta é hora de definir como EPIs as experiencias analizadas é que esta poida ser reproducida, que poida emularse.É dicir, que non sexa unha iniciativa aíllada e que haxa posibilidades de reproducila noutros contextos. 
A caracterización das EPIs supón unha aposta por determinar cales son os trazos definitorios destas, co obxectivo de que podan axudar a outros/as labregos/as ou emprendedores/as a replicar este tipo de experiencias co fin de lograr unha escalabilidade de experiencias semellantes ao longo do pais. De acordo a Gonzalez Molina M. (2007, 41) o reto consiste "...en ampliar la escala de las experiencias agroecológicas (upscaling agroecology), superando el bloqueo institucional y creando una nueva institucionalidad alternativa mucho más favorable. Con ello se busca incrementar significativamente el porcentaje que hoy significa el consumo de productos orgánicos y locales, bajo lógicas agroecológicas, en el conjunto del consumo agroalimentario. Se trata de poner en el centro la cooperación entre los distintos eslabones de la cadena y no la competencia, de tal manera que se supere el aislamiento y la fragmentación de las experiencias". Nese sentido o traballo da rede ReVOLTA é ser un actor máis nese proceso, non so coa publicación de artigos como este, senón tamén na organización de seminarios e lugares de encontro entre diversas experiencias co fin de tecer ecosistemas que colaboren na consecución dunha transición agroecolóxica.

\section{CONCLUSIÓNS}

A investigación da Rede Revolta 1 e 2 sobre a innovación no medio rural hoxe en clave agroecolóxica tivo en conta tanto a bagaxe cultural, como a historia da ciencia labrega e a necesidade imperiosa de definir un futuro agroecolóxico. O estudo sobre o fenómeno das EPI〉S segue en marcha na fase 3 da Rede Revolta e está pendente aínda de dar novos resultados, na lóxica de ir indo máis alá da tecnoloxía como artefacto.

$\mathrm{Na}$ indagación da rede Revolta sobre as EPIs definimos un método de exploración para a identificación de experiencias produtivas innovadoras. Buscamos descubrir aquelas experiencias innovadoras en curso que podían identificarse con modelos propios da transición agroecolóxica cara unha economía sustentable de base orgánica. Definimos un método para avaliar e categorizar as EPIs, pero tamén redefinimos o método no proceso de investigación.

Como resultado do diálogo entre os investigadores da Rede, expertos alleos e outros axentes con presenza no medio rural e coñecemento das súas dinámicas, foise conformando un un amplo abano de experiencias que a xuízo dos participantes entraban dentro desa categorización.

Experiencias que son parte do proceso de transición agroecolóxica debido a que revindicando vaores socioambientais que complementas os económicos (os únicos que se teñen en conta no sistema economicista vixente e dominante), apostan por tecer redes no local, dentro das de comunidades amplas que reivindican valores cooperativos e comunitarios, que tecen desde a pluriactividade e o uso de propostas tecnolóxicas endóxenas, cntroladas polas persoas e as súas comunidades, innovando tamén no ámbito social, adaptándose e reaxindo fronte aos desafíos e limitantes enfrontados nas súas estratexias de 
supervivencia. Transición agroecolóxica que segue en marcha e que precisa de propostas innovadoras, como as recoñecidas neste texto que permitan escalar a agroecoloxía, facela máis presente no medio rural e no sistema agroalimentario do que aquelas experiencias, e todas nós, formamos parte.

A través deste artigo procuramos contribuír a poñer o coñecemento e o diálogo entre expertos, investigadores e axentes sociais ao servizo dun desenvolvemento sustentable no rural, co que dar conta da identificación doutros modelos de innovación que están agromando no pais ${ }^{4}$. A caracterización das EPIS vai alén de ser obxecto de estudo, procura ser tamén un lugar de encontro destas experiencias, onde elas mesmas, a través do diálogo tamén se recoñezan e cooperen alén do que viñan facendo.

E por último cómpre recoñecer a experiencia Arqueixal de Ecoagroturismo, en Albá, Palas de Rei. Trátase de "un lugar especial que ofrece benestar, respectando o medio-ambiente, promovendo un medio rural e agrario sustentábel, desde un punto de vista ecolóxico, económico e social"5. Foi para nós un detonante que nos permitiu comezar a albiscar que se estaban a dar outros xeitos de facer no medio rural e que cumpría estar atentos co obxectivo de analizar a súa potencialidade no camiño cara un futuro sustentable de Galiza.

$4 \quad$ Un avance dos resultados están publicados en Investigadores da Aldea-Rede Revolta (2018) Revoltando á terra. Reinventando o rural, Bolanda. Santiago de Compostela. Tamén poden consultarse todos os resultados e todas as experiencias recollidas ao longo do proxecto da Rede na paxina web http://revolta. usc.gal/

5 http://www.arqueixal.com/agro/aldea.htm 


\section{BILIOGRAFÍA}

Altieri, M. (1983): Agroecología Bases científicas para una agricultura sustentable. Ediciones CETAL.

Corbacho, B. (2017): Intensification of a peasant agriculture and soil fertility in an Atlantic territory: Galicia, 1750-1900. PH D. Thesis USC.

Cuellar, M.; Sevilla E. (2009): “Aportando a la construcción de la Soberanía Alimentaria desde la Agroecología” In Ecología política, № 38 (Exemplar adicado a: La agricultura del siglo XXI), pp. 43-51.

Daly; H. E. (2012): “Economía de estado estacionario. Estancamiento económico y economía de estado estacionario no significan lo mismo; nos enfrentamos a dos alternativas muy distintas" in Papeles de relaciones ecosociales y cambio global. FUHEM Ecosocial, pp. 43-55.

Fernández Prieto, L. (1992): Labregos con ciencia, Xerais.

Fernández Prieto, L. (1997): "Selección de innovaciones en una agricultura atlántica de pequeñas explotaciones. Galicia, 1900-1936. La adopción de las trilladoras mecánicas", in Noticiario de Historia Agraria, no 14, pp. 133-163.

Fernández Prieto, L.; Simón, X.; Vilas, X. M. (1988): “A agroecoloxía e agricultura convencional. A situación galega" in Agroecoloxía na Galiza. Cadernos ADEGA, pp. 7-18.

Fernández Prieto, L. (2016): “O atraso: o éxito dun falso mito. Imaxes contra os tópicos do mundo rural e os labregos" in: Dubert, I. et al., eds., Historia das historias de Galicia, Xerais.

Fitzgerald, D. (2003): Every Farm a Factory: The Industrial Ideal in American Agriculture, Yale UP.

González de M., M.; D. López; G. Guzmán, (2017): "Politizando el consumo alimentario: estrategias para avanzar en la transición agroecológica" in: REDES: Revista do Desenvolvimento Regional, vol. 22, pp. 31-55.

Méndez V. E.; M. Bacon; R. Cohen (2013): “Agroecology as a Transdisciplinary, Participatory, and Action-Oriented Approach”. En Agroecology and Sustainable Food Systems, vol. 27, pp. 3-18.

Ripple, W. J. et al., (2017): "World Scientists' Warning to Humanity: a second notice". En BioScience, vol. 67, no 12 .

Rockström, J. et al., (2009): “A safe operating space for humanity”. En, Nature, vol 461, $\mathrm{n}^{\circ} 24$.

Rogers, E. (2003): Diffusion of Innovations. Free Press.

Schumacher, E. F. (1988): Lo pequeño es hermoso. Orbis.

Shiva, V. (2008): Monocultivos de la mente. Fineo.

Simón, X. e Copena D, (2012): "Enerxía eólica e desenvolvemento rural: Análise da iniciativa da CMVMC de Zobra”. GIEEA e Fundación Juana de Vega. 
Sonnino, R; T. E. Marsden; A. Moragues-Faus (2016): "Relationalities and convergences in food security narratives: towards a place-based approach”. In Transactions, vol, 41, pp. 477-489.

Soto, D. (2006): Historia dunha agricultura sustentable. Xunta de Galicia.

Yearley, D. (2005): "Nature and the environment in science and techonology studies". in: E. J. Hackett et al., eds., The handbook of science and technology studies.3rd de. Cambridge, MA:MIT Press, pp. 921-948. 